\title{
Caracterização da população dos receptores em lista e os submetidos ao transplante de Pâncreas e Pâncreas e-Rim
}

\author{
Characterization of the receptor population as listed and those \\ who were submitted to Pancreas and Pancreas-Kidney transplantation \\ Caracterización de la población de los receptores en lista y los \\ Que fueron sometidos a el trasplante de Páncreas y Páncreas-Riñon
}

\author{
Vivian Cintra', Talita Destro' \\ 'Faculdade de Enfermagem do Hospital Israelita Albert Einstein, \\ Curso de Especialização em Enfermagem Clínica e Cirúrgica. São Paulo, SP
}

Submissão: 20/09/2006

Aprovação: 13/10/2007

\section{RESUMO}

Cerca de 1 milhão de casos do transplante foram registrados no mundo. O primeiro transplante de Pãncreas no Brasil data de 1996 , realizado por uma equipe médica de São Paulo. Este trabalho teve como objetivo caracterizar o perfil sócio-demográfico e epidemiológico dos receptores em lista e os submetidos a este procedimento. Trata-se de estudo um estudo inter-relacional retrospectivo compreendendo o período de 1996 a 2004 . O estudo revelou a predominância de mulheres, da raça branca e, com média de idade de 35 anos. A procedência dos pacientes foi dos estados de São Paulo e Minas Gerais.

Descritores: Transplante de Pâncreas; Transplante de rim; Medidas em epidemiologia.

\begin{abstract}
About 1 million cases of transplantation were registered around the world. The first Pancreas transplantation in Brazil was in 1996 , proceeded by a medical team of São Paulo. The objetctive of this study was to characterize the socio- demographic and epidemiological profile of the receivers in list and those submitted to this procedure. It is an inter-relational retrospective study considereing the period from 1996 to 2004 . Results demonstrated the predominance of women, from white race, and, with an average of 35 years. The origin of the patients was the states of São Paulo and Minas Gerais.

Descriptors: Pancreas transplantation. Kidney transplantation, Measurements in epidemiology.

\section{RESUMEN}

Cerca de 1 millón de casos de trasplante fueron registrados en el mundo. El primer transplante tiene origen en 1996 in Brasil por un equipo de médicos de San Pablo. El objetivo de esto estudio fué caracterizar el perfil sociodemográfico y epidemiológico de los receptores en lista y los sometidos a esto procedimiento. Tratase de un estudio inter-relacional retrospectivo, Que consideró el periodo de 1996 al 2004. El estudio reveló la predomináncia de mujeres de la raza blanca y, con media de edad de 35 años. La procedencia de los pacientes fueram los estados de San Pablo y Minas Gerais.

Descriptores: Trasplante de páncreas; Trasplante de Riñón; Medidas en epidemiología.
\end{abstract}




\section{INTRODUÇÃO}

O transplante de pâncreas visa a normalização da glicose sanguínea do receptor portador de Diabetes Mellitus Tipo I (DM), e é indicado para pacientes com complicações como neuropatias, nefropatias e retinopatias ${ }^{(1-3)}$.

Cerca de um milhão de casos de transplantes foram registrados no mundo inteiro ${ }^{(2,4,5)}$, e segundo o Registro Brasileiro de Transplantes (RBT) foram feitos aproximadamente 240 transplantes de pâncreas isolado e pâncreas-rim em $2003^{(6)}$. O Ministério da Saúde estabelece que, até o ano de 2004 foram realizados cerca de 600 transplantes ${ }^{(7)}$.

O primeiro transplante foi realizado em 1966 por Kelly e Lillehei nos $\mathrm{EUA}^{(4)}$. A partir de 1996 uma eQuipe médica iniciou o programa de transplante de pâncreas na cidade de São Paulo(2) .

Os estudos revelam Que os pacientes a serem submetidos ao transplante são avaliados Quanto à idade, sexo, peso (doador e receptor), tempo de Diabetes Mellitus, estágio de complicações diabéticas, técnica de transplante e esquema de imunossupressão $0^{(3,8,9)}$.

Segundo a Associação Brasileira de Transplante de Órgãos ABTO a distribuição do número de transplante de órgãos realizados no Brasil no período de 1997 a 2004 no Que se refere ao transplante de pâncreas-rim e pâncreas isolado, apresentaram os respectivos valores, 610 e 198, demonstrando o progresso terapêutico desde a sua inserção ${ }^{(10)}$. A lista de espera para o transplante de pâncreasrim e pâncreas, respectivamente são 242 e 121, apresentados pelo Ministério da Saúde em Setembro de 2004, representando 63, I 8\% e 56,80\% inscritos no estado de São Paulo, revelando a maioridade populacional na Região Sudeste do Brasil ${ }^{(11)}$.

O principal objetivo deste tipo de terapêutica é o controle do Diabetes Mellitus, revertendo a vida dos pacientes insulinodependentes, não necessitando mais do uso de insulina e as complicações da neuropatia, não desenvolvendo nefropatia diabética, contribuindo para a melhora da Qualidade de vida ${ }^{(1)}$.

Estudos propõem a independência da insulina na realização do transplante de pâncreas isolado, às custas da imunossupressão, sem a necessidade de transplante renal concomitante. Porém, há controvérsias significativas da dependência da insulina, mesmo após o transplante de pâncreas ${ }^{(12)}$.

O transplante de pâncreas é mais caro do Que o custo anual do tratamento com insulina, mas, ao longo de várias décadas, pode trazer vantagens em relação a custos, se evitar cegueira e insuficiência renal ${ }^{(13)}$.

Poucos artigos trazem informações sobre a neuropatia e a nefropatia relacionadas ao processo inicial da patologia. Mas sabese Que a retinopatia é mais comum do Que a nefropatia e que a presença e severidade da retinopatia foi associada à longa duração da diabetes e a um nível aumentado de $\mathrm{HbA}$. Sexo, idade, contagem de células brancas e nível de potássio sérico não foram associados à severidade da retinopatia ${ }^{(12)}$.

A participação da enfermagem na área dos transplantes está presente na história desde os primórdios da realização do primeiro transplante de órgãos no Brasil, onde a enfermagem gerenciou e assistenciou toda a complexidade da terapêutica, junto à equipe pioneira de transplante cardíaco, pelo Dr. Euryclides Zerbini, no Hospital das Clínicas da Faculdade de Medicina de São Paulo(12).
A caracterização da população submetida à complexidade deste tipo de técnica terapêutica, nos revelará os aspectos epidemiológicos, sócio-culturais destes receptores, a fim de estabelecer melhora da assistência de enfermagem, de forma eficaz nos períodos peri-operatório.

A dinâmica assistencial da enfermagem compreende a Qualidade da assistência voltada para as necessidades humanas básicas de forma individualizada, proporcionando condutas de enfermagem condizentes com as características do indivíduo. Para tanto, é necessário conhecer as características epidemiológicas da população estudada e a partir disto construir a prática de enfermagem com evidência em busca do melhor resultado assistencial aos transplantados de pâncreas.

Assim, o objetivo deste estudo foi caracterizar o perfil sociodemográfico e epidemiológico dos receptores em lista e submetidos ao transplante de pâncreas e pâncreas-rim no Brasil no período de 1996 a 2004 realizados pela equipe pioneira.

\section{MÉTODO}

Estudo inter-relacional retrospectivo. Compreendeu o período de 1996 a 2004, referenciado na realização do primeiro transplante de pâncreas e pâncreas-rim no Brasil ao término do ano de 2004 pela equipe pioneira.

O projeto foi enviado à Comissão Científica da Faculdade de Enfermagem do Hospital Israelita Albert Einstein e posteriormente ao Comitê de Ética em Pesquisa do Hospital Israelita Albert Einstein. Os dados foram obtidos através do grupo de cirurgiões especialistas em transplantes de órgãos na cidade de São Paulo, junto aos prontuários do Estudo do Receptor de Transplante de Pâncreas-Rim. Este formulário foi elaborado e validado pelo grupo de cirurgiões especialistas.

A população e amostra constaram de pacientes em lista juntamente com os submetidos ao transplante de pâncreas e pâncreas -rim. Desta forma, a população compreendeu 402 formulários, dos Quais 61 foram excluídos, utilizando-se $34 \mathrm{I}$ formulários apresentados como amostra da pesquisa.

Os critérios de exclusão foram os formulários com dados ilegíveis ou duplicidade de informações. As informações não utilizadas do instrumento de pesquisa foram: Cirurgias e transplantes anteriores, descompensações, Quadro clínico, hospital onde dialisa, fístulas, número de transfusões, local e tipo de diálise, diurese residual e outras complicações.

As variáveis sociodemográficas e epidemiológicas, utilizadas foram: idade, sexo, raça, convênio, cidade, tipo sanguíneo, tempo de Diabetes Mellitus, tipo de diálise, presença de retinopatia, neuropatia e nefropatia.

Os dados coletados foram lançados em banco de dados aplicativos do Microsoft Excel 7.0. Apresentação dos resultados com as médias, medianas, desvio-padrão, e aplicação de teste para análise da variância.

\section{RESULTADOS}

\section{Fase de Entrada}

A figural revela a distribuição da população em lista e submetida ao transplante de pâncreas e pâncreas-rim. Inicia-se em 1997 com 100\% (0I paciente) do sexo feminino e em 1998 50\% do sexo 


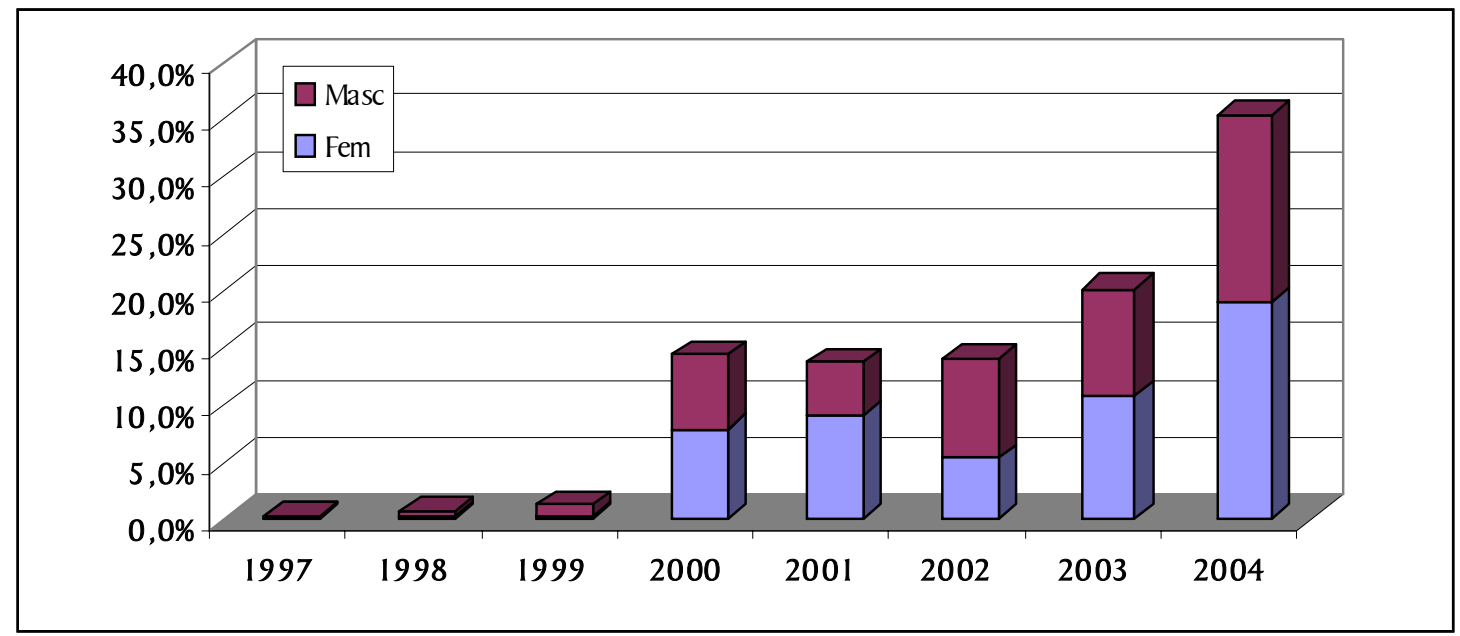

Figura 1. Distribuição da população do transplante de pâncreas e pâncreas-rim, Quanto ao sexo e período de 1997 a 2004. São Paulo, 2005.

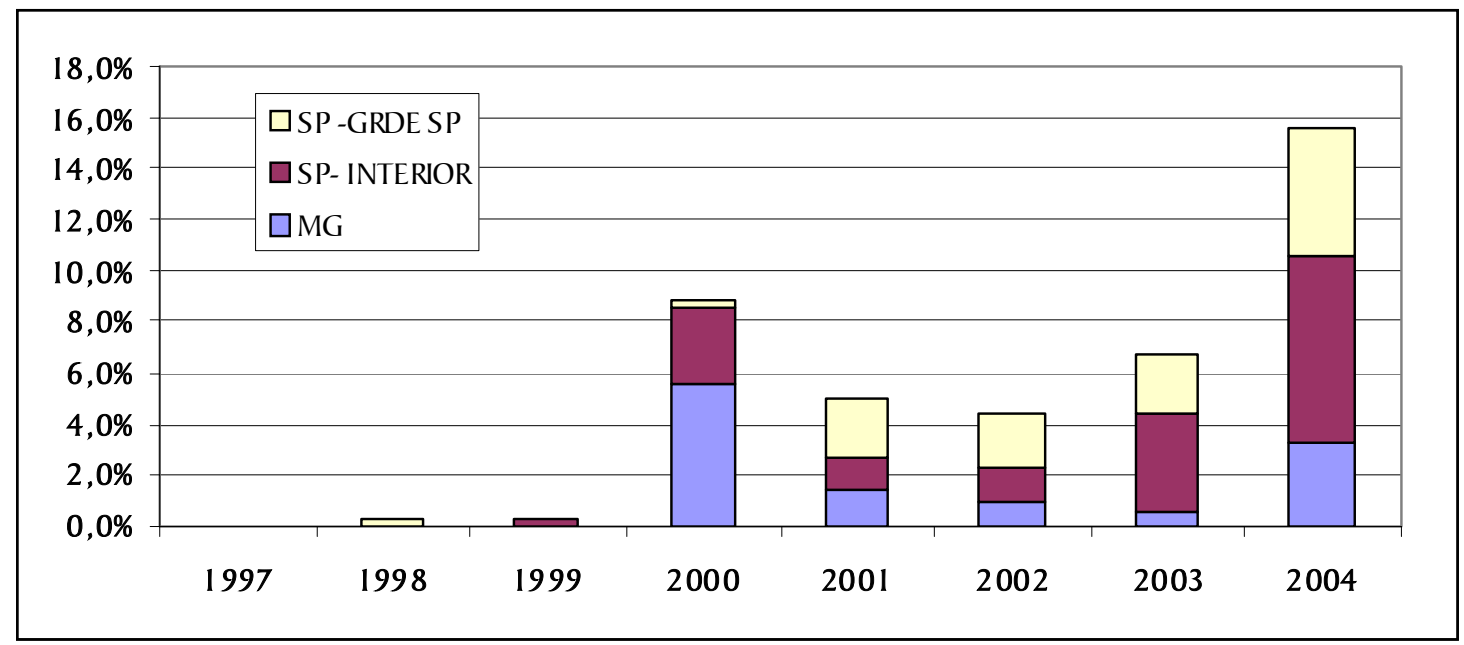

Figura 2. Distribuição da população, segundo a procedência nos anos 1997 a 2004. São Paulo, 2005.

feminino (0I paciente) e 50\% do sexo masculino (0I paciente). Em 1999 a prevalência foi do sexo masculino com $75 \%$ (3 pacientes) e 25\% do sexo feminino ( 1 paciente).

A partir do ano de 2000 houve um crescimento significativo de pacientes, $55 \%$ do sexo feminino ( 49 pacientes) e $45 \%$ do sexo masculino (22 pacientes).

Esta taxa manteve-se praticamente a mesma durante o ano de $200166 \%$ do sexo feminino (3 I pacientes) e $34 \%$ do sexo masculino ( 16 pacientes). Já em 2002 houve a inversão, onde 38\% foram do sexo feminino ( 18 pacientes) e $63 \%$ do sexo masculino (30 pacientes).

A partir de 2003, houve um aumento de pacientes transplantados de $43,75 \%$ (69 pacientes), onde $54 \%$ do sexo feminino ( 37 pacientes) e $46 \%$ do sexo masculino ( 32 pacientes).

$\mathrm{O}$ ano de 2004 expressa o aumento de 75,36\% (12 1) pacientes em relação ao ano de 2003.

Os dados descritos basearam-se no total de 341 formulários.

Na figura 2, os anos de 1997, 1998 e 1999 não foram de grande relevância.
A partir do ano de 2000, 63,3\% (19 pacientes) foram provenientes do Estado de Minas Gerais, seguidos de 33,3\% ( 10 pacientes) do Interior de São Paulo.

No ano de 2001, 47,1\% (8 pacientes) foram provenientes da Grande São Paulo, seguidos de 29,4\% (5 pacientes) do Estado de Minas Gerais e 23,5\% (4 pacientes) do Interior de São Paulo.

Em 2002, 46,7\% (7 pacientes) foram provenientes da Grande São Paulo, seguidos de 33,3\% (5 pacientes) do Interior de São Paulo e 20\% (3 pacientes) do Estado de Minas Gerais.

Em 2003, a situação inverte-se com 56,5\% (13 pacientes) provenientes de do Interior de São Paulo, 34,8\% (8 pacientes) da Grande São Paulo e 8,7\% (2 pacientes) do Estado de Minas Gerais.

Em relação ao ano de 2003 para 2004 revela-se um aumento de $92,31 \%$ de pacientes no Interior de São Paulo (25 pacientes), 11 12,50\% na Grande São Paulo (17 pacientes) e em Minas Gerais $450,00 \%$ ( 1 I pacientes).

Foram utilizados 141 formulários representando 41,34\% do total da amostra.

Na Figura 3, o Diabetes Mellitus foi apresentado por tempo de 
permanência da patologia em relação às complicações associadas. Portanto, o tempo percorrido da DM utilizado neste gráfico, compreende os períodos de 1 a 10 anos, 10 a 20 anos, 20 a 30 anos, 30 a 40 anos e 40 a 50 anos. A média de tempo de pacientes com Diabetes Mellitus corresponde a 21,16 anos.

O período de 10 a 20 anos, obteve um crescimento alarmante onde 25\% (74 pacientes) apresentaram neuropatias, 40,5\% (120 pacientes) retinopatias e $34,5 \%$ ( 102 pacientes) nefropatias. De 20 a 29 anos, as complicações foram de 23,7\% (75 pacientes) neuropatias, 45, I\% (143 pacientes) retinopatias e 31,2\% (99 pacientes) nefropatias. O período de 30 a 40 anos ocorre o decréscimo das complicações $20,5 \%$ ( 16 pacientes) apresentaram neuropatias, 39,7\% (3 I) retinopatias, e 39,7\% (31) nefropatias.

Considerando os dados da figura, a Diabetes Mellitus pode relacionar-se a um ou mais tipos de complicações, haja vista os casos de retinopatias, associados a nefropatias e neuropatias. Neste caso, relatou-se separadamente cada tipo de complicações, com intuito de facilitar a identificação e compreensão das patologias associadas a diabetes.

Nesta figura utilizou-se 34l formulários.

Nota-se na figura 4, Que no período de 0 a 5 anos a realização do procedimento hemodiálise 74,0\% (91 pacientes) é marcante, seguido de $26,0 \%$ (32 pacientes) Que realizaram diálise. Contudo, após 5 a 10 anos de procedimento ocorre o abrupto decréscimo, sendo 84,6\% (1 1 pacientes) em hemodiálise, 15,4\% (2 pacientes) em diálise. Em 10 a 15 anos de procedimento, 100\% (3 pacientes) realizaram hemodiálise.

A amostra desta população compreendeu 139 pacientes.

\section{DISCUSSÃO E CONCLUSÃO}

Este estudo revelou as principais características da população em lista e submetida a esta prática terapêutica, Quanto à idade, sexo, raça, procedência, tempo de Diabetes Mellitus e complicações, tempo de procedimento e tipo de diálise.

A taxa de mulheres submetidas à prática terapêutica prevalece praticamente em todos os anos. A média de idade dos pacientes é de 35, I anos, e a prevalência racial é a branca.

Ressaltamos Que 11,1\% (38 pacientes) transplantaram o rim anteriormente.

O baixo índice de transplantes nos anos 1997 a 1999, relata o início das atividades transplantadoras da equipe, coincidentemente

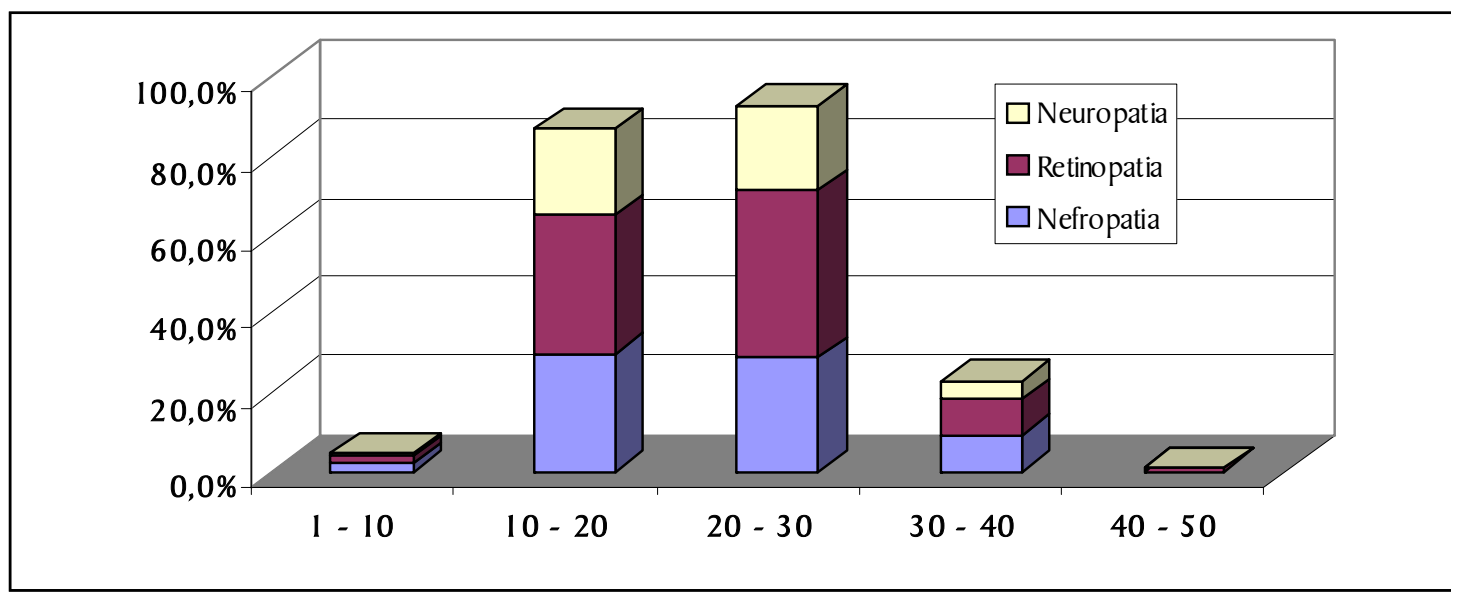

Figura 3. Distribuição epidemiológica da neuropatia, nefropatia e retinopatia, segundo o tempo em anos da Diabetes Mellitus. São Paulo, 2005.

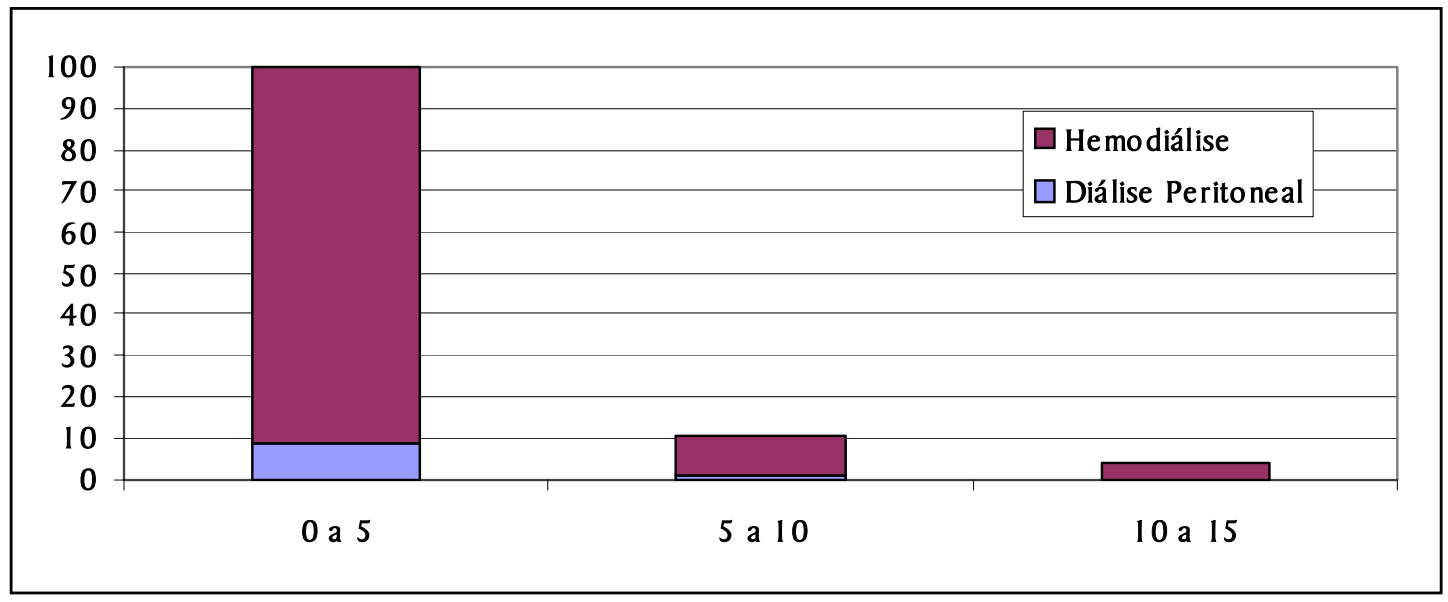

Figura 4. Distribuição do tipo de diálise, segundo o tempo de procedimento. São Paulo, 2005. 
com a Lei n.9434 de 04/02/97 Que dispõe sobre a remoção de tecidos e partes do corpo humano para fins de transplantes, tratamento e dá providências ${ }^{(14)}$. Esta lei causou várias controvérsias, discussões, expondo a vida civil e moral da população, através dos documentos de registro geral e da habilitação, desfavorecendo os transplantes.

O ano de 2004 foi considerado pelo Ministério da Saúde o ano dos transplantes, devido a campanhas publicitárias incentivando a doação de órgãos e tecidos ${ }^{(15)}$.

A região Sudeste do Brasil é a maior região transplantadora no país, ressaltando o Estado de São Paulo e Minas Gerais. Sabe-se da presença de equipes transplantadoras no Estado de Minas Gerais, porém a partir do ano de 2001 há um decréscimo dos pacientes transplantados, o Que contribui para o maior contingente de pacientes transplantados no Estado de São Paulo, além dos pacientes provenientes do próprio Estado ${ }^{(16)}$.

A prevalência de pacientes proveniente de outros Estados Brasileiros não foi considerada, pela baixa incidência, destacandose apenas os três locais citados.

O índice de pacientes portadores de Diabetes Mellitus, cujas complicações manifestam-se pela retinopatia, condiz com a incidência de altos relatos de amauroses/cegueira, revelados durante o estudo.

Após esta pesquisa, tendo como base no perfil da população estudada, as possibilidades de elaboração de novos trabalhos será mais dinâmica, contribuindo para a melhora da assistência.

\section{REFERÊNCIAS}

I. Barker CF, Brayman KL, Markman JF, Naji A, Olthoff KM, Shaked A. Transplante de órgãos abdominais. In: Townsend CM, Beauchamp RD, Evers BM, Mattox KL. Sabiston: tratado de cirurgia: as bases biológicas da prática cirúrgica moderna. $16^{\mathrm{a}}$ ed. Rio de Janeiro (RJ): Guanabara Koogan; 2003. p. 497-513.

2. Perosa M, Genzini T, Gil AO, Goldestein PJG, Pandullo F, Fornasari G, et al. Transplante de pâncreas isolado (órgão total) com drenagem vesical: relato do primeiro caso do Brasil. ArQ Bras Endocrinol Metab 1999; 43 (5): 393-8.

3. Ko narová R, Saudek F, Hrachovinová T, Adamec M, Bouèek $P$, Jedináková $T$. The Quality of life of pancreas recipients with type-I diabetes. Transplant Proc 200 I; 33 (1-2): 1890.

4. Tacconi MRO, Lee MP, Gomes AEO, Miranda MP, Genzini T, Rodrigues IJG. Transplante de pâncreas: relato de caso e revisão da literatura. Rev Medicina 1997; 76 (4): 235-48.

5. Perosa M, Genzini T. Pancreas-kidney transplantation in Brazil: current difficulties and perspectives. Tranplant Proc 1999; 31(7): 3005-6.

6. Associação Brasileira de Transplante de Órgãos. Registro Bras Transplantes 2003; 9: 2.

7. Ministério da Saúde (BR). Captação e transplante de órgãos no Brasil [online]. 2003 [citado em: I 5 mar 2005]. Disponível em: URL: http://dtr2001.saude.gov.br/transplantes/ index_gestor.htm

8. Roza BA. Impacto da legislação dos transplantes de órgãos sobre médicos e enfermeiros de uma comunidade universitária [dissertação]. São Paulo (SP): Universidade Federal de São Paulo; 2000.

9. Lo A, Stratta RJ, Egidi MF, Shokouh-Amiri MH, Grewal HP,
Kizilisik AT, et al. Outcomes of simultaneous kidney-pancreas transplantation in African-American recipients: a case-control study. Clin Transplant 2000; 14 (6): 572-9.

10. Associação Brasileira de Transplante de Órgãos. Gráficos 2004. Rev Bras de Transplant [online]. 2004. [citado em: 7 abr 2005]. Disponível em: URL: http://www.abto.org.br/ profissionais/profissionais.asp

11. Tacconi M. Transplante de pâncreas: relato de caso e revisão de literatura. Rev Medicina 1977; 76 (4): 235-48.

12. Klein R, Zinman B, Gardiner R, Suissa S, Donnelly SM, Sinaiko AR. The relationship of diabetic retinopathy to preclinical diabetic glomerulopathy lesions in type I diabetic patients: the reninangiotensin system study. Diabetes 2005; 54 (2): 527-33.

13. Ferrarini CDT, Miller MLG, Mello MZR. Transplante de coração. Rev Bras Enferm 1968; 2 1 (6): 529-37.

14. Secretaria de Estado da Saúde (SP). Lei n. 9434, de 4 de fevereiro de 1997. Dispõe sobre a remoção de órgãos, tecidos e partes do corpo humano para fins de transplante e tratamento e dá outras providências. Diário Oficial do Estado de São Paulo; 1997 Fev 4. [citado em: 22 nov 2005]. Disponível em: URL: http://www.saude.sp.gov.br/biblioteca/html/catalogotransplantes.html.

15. Adote. Aliança Brasileira pela Doação de Órgãos e Tecidos. Brasil bate novo recorde na área de transplantes [online]. 2005. [citado em: 2 I nov 2005]. Disponível em: URL: http:/ /www.adote.org.br/noticias/07.2004.htm

16. Secretaria do Estado de Saúde (MG). Transplantes realizados [online]. 2004. [citado em: 22 nov 2005]. Disponível em: URL: http://www.saude.mg.gov.br/transplantes_realizados.htm 